Article

\title{
Anti-Inflammatory Properties of MSF, a Lactiplantibacillus plantarum K8 Lysate Fermented with Filipendula glaberrima Extract
}

\author{
Kyeong-Hun Choi ${ }^{1}$, Jonghyo Hong ${ }^{1}$, Ki-Young Kim ${ }^{1} \mathbb{D}$, Hangeun Kim ${ }^{2, *}{ }^{\mathbb{D}}$, Sanghyun Lee ${ }^{3} \mathbb{D}$, Yunji Lee ${ }^{4}$ \\ and Dae-Kyun Chung ${ }^{1,5, *}$ \\ 1 Graduate School of Biotechnology, Kyung Hee University, Yongin 17104, Korea; \\ chlkh6599@naver.com (K.-H.C.); liil12@naver.com (J.H.); kiyoung@khu.ac.kr (K.-Y.K.) \\ 2 Research and Development Center, Skin Biotechnology Center Co., Ltd., Yongin 17104, Korea \\ 3 Department of Plant Science and Technology, Chung-Ang University, Anseong 17546, Korea; slee@cau.ac.kr \\ 4 Department of Herbal Crop Research, National Institute of Horticultural and Herbal Science, \\ Eumseong 27709, Korea; yoong0625@korea.kr \\ 5 Skin Biotechnology Center, Kyung Hee University, Suwon 16229, Korea \\ * Correspondence: hkim93@khu.ac.kr (H.K.); dkchung@khu.ac.kr (D.-K.C.); Tel.: +82-31-201-2465 (H.K.); \\ +82-31-201-2465 (D.-K.C.); Fax: +82-31-202-3461 (D.-K.C.)
}

check for

updates

Citation: Choi, K.-H.; Hong, J.; Kim,

K.-Y.; Kim, H.; Lee, S.; Lee, Y.; Chung,

D.-K. Anti-Inflammatory Properties

of MSF, a Lactiplantibacillus plantarum K8 Lysate Fermented with Filipendula glaberrima Extract. Appl. Sci. 2022, 12, 2602. https://doi.org/10.3390/ app12052602

Academic Editors: Isabel Rodríguez Amado, Lorenzo M. Pastrana and Pablo Fuciños

Received: 25 January 2022

Accepted: 28 February 2022

Published: 2 March 2022

Publisher's Note: MDPI stays neutral with regard to jurisdictional claims in published maps and institutional affiliations.

Copyright: () 2022 by the authors. Licensee MDPI, Basel, Switzerland. This article is an open access article distributed under the terms and conditions of the Creative Commons Attribution (CC BY) license (https:// creativecommons.org/licenses/by/ $4.0 /)$.

\begin{abstract}
Inflammation plays an important role in the pathogenesis of metabolic syndrome, which increases the risk of heart disease, stroke, type 2 diabetes, atherosclerosis, non-alcoholic fatty liver disease (NAFLD), and obesity. Here, we produced potent anti-inflammatory probiotic lysates, termed MSF (miracle synergistic material made using Filipendula glaberrima), using fermentation with F. glaberrima extracts. MSF inhibited lipopolysaccharide (LPS)-induced tumor necrosis factor (TNF)- $\alpha$ production through down-regulation of c-Jun N-terminal kinase (JNK) signaling. MSFinduced tolerance for TNF- $\alpha$ was mediated by induction of TNF alpha-induced protein 3 (TNFAIP3 or A20). On the other hand, MSF showed a synergistic effect on interleukin (IL)- $1 \beta$ production in LPS-stimulated human monocytic leukemia cell line (THP-1 cells). This synergistic effect of the combination of MSF and LPS might be mediated by nuclear factor kappa B (NF-kB) signaling. The inhibitory effect of TNF- $\alpha$ and synergistic effect of IL-1 $\beta$ due to combining MSF and LPS were significantly higher than those of a combination of L. plantarum K8 lysates and LPS. The MSF and LPS combination showed reduced mouse mortality compared to a combination of L. plantarum K8 lysates and LPS, which correlated with decreased levels of cytokines, hepatic alanine aminotransferase (ALT), and aspartate aminotransferase (AST) in the blood and liver. These results show that probiotic lysates fermented with natural extracts such as F. glaberrima have higher anti-inflammatory efficacy than conventional probiotic lysates or natural extracts.
\end{abstract}

Keywords: Lactiplantibacillus plantarum K8; Filipendula glaberrima; probiotic lysates; anti-inflammation; miracle synergy

\section{Introduction}

Lactic acid bacteria, important microorganisms used in the food industry, produce lactic acid using various carbon sources. In food, they produce aromatic components such as acetoin or diacetyl and polysaccharides such as dextran, resulting in improved material properties [1,2]. These metabolites prevent the growth of harmful bacteria in the intestine, regulate immunity, and mitigate skin diseases such as atopy and psoriasis. In addition, probiotics can improve the health of the host, including suppressing obesity and metabolic syndrome [3-6]. Lactiplantibacillus plantarum is an aerobic bacillus bacterium belonging to the category of Gram-positive bacteria. Its primary characteristic is that it breaks down polysaccharides such as galactose and arabinose [7]. Among lactic acid bacteria, L. plantarum 
seems to have a strong anti-inflammatory effect [8-10]. It is mainly present in fermented vegetable-based foods, and the L. plantarum K8 strain isolated from kimchi is particularly active in sour kimchi. In a recent study, we reported that L. plantarum K8 lysates showed anti-inflammatory effects and alleviated lipopolysaccharide (LPS)-induced septic shock in mice [11]. However, the anti-inflammatory efficacy of L. plantarum K8 lysates is lower than that of lipoteichoic acid (LTA) isolated from the L. plantarum K8 cell wall [12], and to induce a similar anti-inflammatory effect using lysates, a five-fold increase in lysates must be used. Therefore, we prepared lysates fused with probiotics and Filipendula glaberrima to induce a stronger anti-inflammatory effect.

F. glaberrima NAKAI, also called Korean meadowsweet, is a rosaceae plant found in the mountains north of central Korea. It can be used for medicinal purposes such as analgesic effects; sedative effects; treatment of gout, neuralgia, and arthritis; and anti-spasmodic effects. There are various species of Filipendula, and these extracts are known to have pharmacological activity that can treat inflammation, infection, ulcers, oxidation, wounds, liver disease, cancer, coagulation, and diabetes [13-16]. The leaves, flowers, stems, and roots of Filipendula have been used to treat various diseases, and active ingredients such as monotropitin, $(+)$-catechin, and $\beta$-sitosterol $3-\mathrm{O}-\beta$-D-glucoside have been isolated from their extracts [17].

In the current study, to prepare probiotic lysates that induce increased anti-inflammatory effects, we created MSF (miracle synergy material made using F. glaberrima) using L. plantarum K8 and F. glaberrima extracts. The superior anti-inflammatory efficacy of MSF was examined and compared to that of L. plantarum K8 lysates.

\section{Materials and Methods}

\subsection{Cell Culture}

THP-1 cells, a human monocyte-like cell line, were maintained in Roswell Park Memorial Institute (RPMI)-1640 medium supplemented with $10 \%$ heat-inactivated fetal bovine serum (FBS), $100 \mu \mathrm{g} / \mathrm{mL}$ penicillin, and $100 \mu \mathrm{g} / \mathrm{mL}$ streptomycin at $37^{\circ} \mathrm{C}$ in a humidified $5 \% \mathrm{CO}_{2}$ incubator. The cells were seeded onto 96- or 6-well plates for enzyme-linked immunosorbent assay (ELISA) and Western blot assay, respectively. After incubation for $24 \mathrm{~h}$, cells were stimulated with lipopolysaccharide (LPS, Escherichia coli 055:B5; Sigma-Aldrich, St. Louis, MO, USA) and/or MSF. To examine the role of suppressor of cytokine signaling 1 (SOCS-1) and tumor necrosis factor- $\alpha$-induced protein 3 (A20) (Cat. No. 1027416 and SI00087010, respectively, Qiagen), THP-1 cells were transiently transfected with siRNA, and the tumor necrosis factor-alpha $(\mathrm{TNF}-\alpha)$ level was examined using the ELISA method. To block LPS-mediated signaling pathways, cells $\left(1 \times 10^{4}\right.$ cells /well $)$ were pre-incubated with inhibitors $(10 \mu \mathrm{M})$ such as Akt, extracellular signal-regulated kinase (ERK), c-Jun Nterminal kinase (JNK), nuclear factor-kappa B (NF-kB), phosphoinositide 3-kinase (PI3K), and p38 (Sigma-Aldrich, St. Louis, MO, USA) for $30 \mathrm{~min}$, followed by incubation with $0.5 \mu \mathrm{g} / \mathrm{mL}$ of LPS for the indicated times. Culture supernatants were subjected to an analysis of cytokine production by ELISA. For detailed experimental methods for Western blot and ELISA, refer to Sections 2.4 and 2.5, respectively.

\subsection{Preparation $M S F$}

L. plantarum K8 was cultured in De Man, Rogosa, and Sharpe (MRS) broth (BD Bioscience, San Jose, CA, USA) containing F. glaberrima extracts at $37^{\circ} \mathrm{C}$ overnight and then harvested by centrifugation at $8000 \mathrm{rpm}$ for $8 \mathrm{~min}$. Bacteria were re-suspended in deionized water and disrupted by a microfluidizer (MN400BF, Micronox, Seongnam, Korea) 5 times at 27,000 psi. Bacterial lysates dubbed 'MSF' were freeze-dried (PVTFD 20R, iLShinBioBase, Dongducheon, Korea) and re-suspended for subsequent experiments. As a control, unfermented L. plantarum K8 lysates were prepared in a similar manner. 


\subsection{Cell Viability Test (Trypan Blue Assay)}

THP-1 cells were seeded onto 96-well plates and incubated overnight. The cells were treated with MSF $(25,50,100,200 \mu \mathrm{g} / \mathrm{mL})$ for $18 \mathrm{~h}$ and/or LPS $(31.25,62.5,125,250,500$, $1000 \mathrm{ng} / \mathrm{mL}$ ) for $4 \mathrm{~h}$. A $0.4 \%$ solution of trypan blue (Sigma-Aldrich) was added to the cells. Cell viability was calculated by dividing the number of viable cells (unstained) by the number of cells initially seeded.

\subsection{Western Blot}

THP-1 cells stimulated with LPS and/or MSF were harvested and lysed with $2 \times$ Laemmli buffer. Denatured proteins were separated by $12 \%$ SDS-PAGE in a Tris/glycine/SDS buffer ( $25 \mathrm{mM}$ Tris, $250 \mathrm{mM}$ glycine, $0.1 \%$ SDS) and transferred onto PVDF membranes (EMD Millipore, Burlington, MA, USA). Membranes were blocked with TBST (20 mM Tris$\mathrm{HCl}, 150 \mathrm{mM} \mathrm{NaCl}, 0.1 \%$ Tween 20) containing $5 \% \mathrm{BSA}$ and treated with primary antibodies such as anti-phospho-NFKB p65 (\#3033), anti-phospho-SAPK/JNK (\#9251), anti-phosphop38 (\#9211), anti-phospho-p44/42 (\#9101), anti-A20 (\#5630) (Cell Signaling Technology, Danvers, MA, USA), anti-SOCS1 (sc-518028), and anti- $\beta$-actin HRP (sc-47778) (Santa Cruz Biotechnology, Santa Cruz, CA, USA) for $2 \mathrm{~h}$ at RT. After washing the membrane with TBST, HRP-conjugated anti-mouse (\#31430, Invitrogen, Carlsbad, CA, USA) or anti-rabbit (sc-2357, Santa Cruz Biotechnology) secondary antibodies were incubated with membranes for $2 \mathrm{~h}$ at RT. After washing the membranes four times in TBST, protein bands were detected using ECL reagents (Thermo Fisher Scientific, Waltham, MA, USA) and exposed to X-ray film.

\subsection{ELISA}

After THP-1 cells were stimulated with LPS and / or MSF, culture supernatants were collected and used for cytokine ELISA assays. The human TNF- $\alpha$ capture antibody (\#MAB610), human TNF- $\alpha$ biotinylated antibody (\#BAF210), human interleukin (IL)-1 $\beta /$ IL-1F2 DuoSet ELISA (\#DY201-05), mouse TNF- $\alpha$ capture antibody (\#AF-410-NA), mouse TNF- $\alpha$ biotinylated antibody (\#BAF410), mouse IL-1 $\beta$ capture antibody (\#MAB401), and mouse IL-1 $\beta$ biotinylated antibody (\#BAF401) were used according to the manufacturer's instructions (R\&D Systems, Minneapolis, MN, USA).

\subsection{Real-Time PCR}

Real-time PCR was performed to examine mRNA levels of SOCS-1 and A20. Briefly, total RNA was extracted from THP-1 cells stimulated with LPS and MSF. cDNA was synthesized using Prime Script ${ }^{\mathrm{TM}}$ RT Master Mix (Takara, Shiga, Japan). Real-time PCR amplification was conducted using a CFX Connect ${ }^{\mathrm{TM}}$ Real-Time PCR Detection System (Bio-Rad, Hercules, CA, USA), and the quantities of PCR products were detected using TB Green ${ }^{\mathrm{TM}}$ Premix EX Taq ${ }^{\mathrm{TM}}$ II (Takara). The following forward and reverse primer pairs were used: $5^{\prime}$ GTCTTCACCACCATGGAGAA-3' and $5^{\prime}$-AGGAGGCATTGCTGATGAT-3' for human glyceraldehyde 3-phosphate dehydrogenase (GAPDH) mRNA, 5'-GTGCACGCAGCATTAACTGG$3^{\prime}$ and $5^{\prime}$-GGAGGGTACCCACATGGTTC-3' for human SOCS-1 mRNA, and 5'CAGTCTGCAGTCTTCGTGGC- $3^{\prime}$ and $5^{\prime}$-GGTGTGATCTCTCTTGGCGG- $3^{\prime}$ for human A20 mRNA. The expression of mRNA was normalized using human or mouse GAPDH mRNA.

\subsection{Mouse Study}

Male Balb/c mice (7 weeks old, $\mathrm{n}=8$ ) purchased from Narabiotech (Seoul, Korea) were kept in individual cages at $24 \pm 2{ }^{\circ} \mathrm{C}$ and $50 \pm 10 \%$ moisture conditions. Mouse care and use were in accordance with the guidelines of the Animal Ethics Committee of Kyung Hee University (KHUASP (GC)-18-033, 2018). Mice were intraperitoneally (i.p.) injected with LPS with or without MSF at the concentrations indicated in the figures. The mortality rate of mice was monitored over 5 days in $12 \mathrm{~h}$ intervals. Serum levels of cytokines such as TNF- $\alpha$ and IL-1 $\beta$ as well as aspartate aminotransferase (AST) and alanine aminotransferase (ALT) were measured using ELISA kits (Biovision, CA, USA). Liver was collected from 
each mouse for histological analysis and immunohistochemistry. Liver homogenates were also prepared for analyses using real-time PCR and western blot.

\subsection{Statistical Analysis}

The representative results of three independent experiments are shown as the mean \pm standard deviation. Statistical analyses were conducted with one-way analysis of variance (ANOVA, San Francisco, CA, USA) followed by Tukey's honestly significant difference (HSD, Post Falls, ID, USA) post hoc test, two-way ANOVA, or unpaired twotailed $t$-test. Differences were considered statically significant when the $p$-value was $<0.05$. GraphPad Prism 5 software (Ver. 5.01) was used for the analysis (GraphPad Software, Inc., San Diego, CA, USA).

\section{Results}

\subsection{MSF Inhibited LPS-Induced TNF- $\alpha$ Production}

TNF- $\alpha$ production, which can cause acute and chronic inflammatory diseases [18], was increased by LPS in THP-1 cells in a dose-dependent manner (Figure 1A). When cells were stimulated with MSF, TNF- $\alpha$ production was increased in a dose-dependent manner, but the effect was only one-tenth that of LPS (Figure 1B). Interestingly, TNF- $\alpha$ production was inhibited when cells were stimulated with MSF followed by LPS treatment (Figure 1C), indicating that MSF has an anti-inflammatory effect against LPS. LPS treatment did not induce THP-1 cytotoxicity at the indicated concentrations (Figure 1D). The combination treatment of LPS and MSF also did not induce cytotoxicity, suggesting that MSF-induced TNF- $\alpha$ inhibition was not mediated by cytotoxicity (Figure 1E).

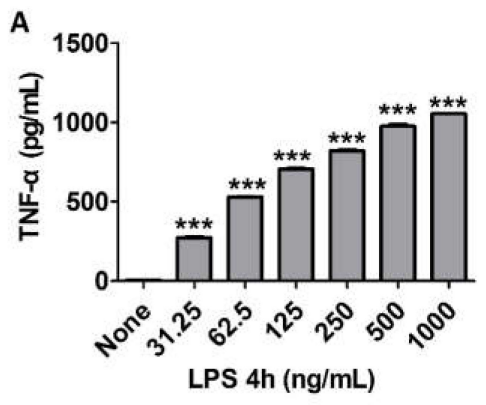

D

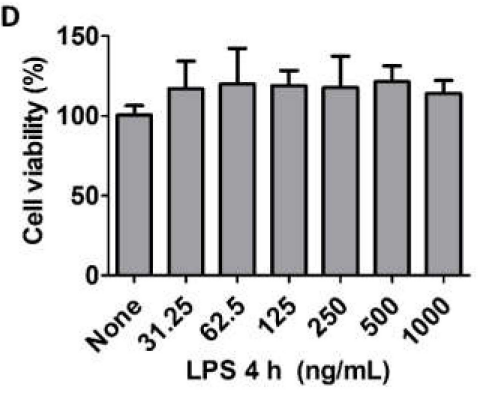

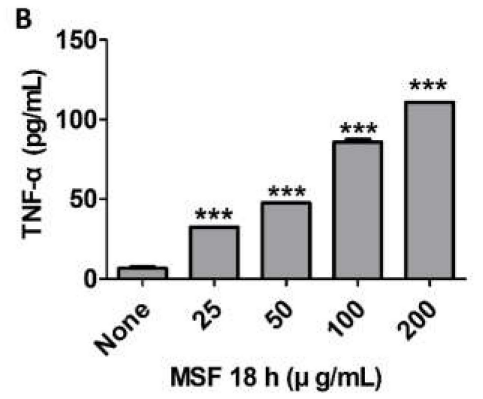
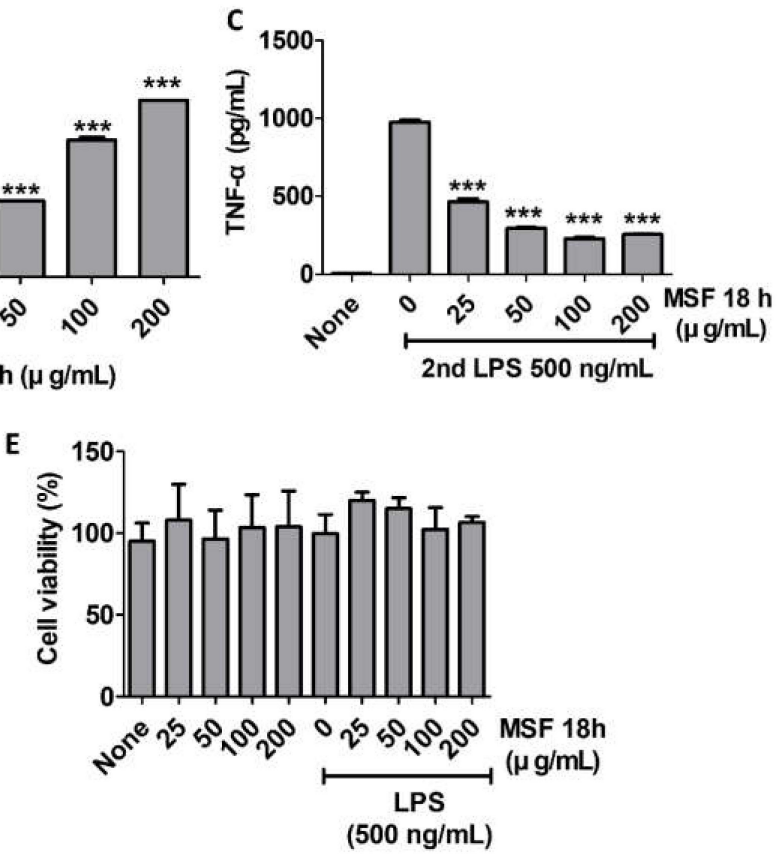

Figure 1. TNF- $\alpha$ expression in THP-1 cells by MSF and LPS treatment. (A) THP-1 cells were treated with lipopolysaccharide (LPS) at the indicated concentration for $4 \mathrm{~h}$. (B) THP-1 cells were treated with MSF at the indicated concentration for $18 \mathrm{~h}$. (C) THP-1 cells were pretreated with MSF at the indicated concentration for $18 \mathrm{~h}$ and were retreated with LPS at a concentration of $500 \mathrm{ng} / \mathrm{mL}$ for $4 \mathrm{~h}$. The level of tumor necrosis factor-alpha (TNF- $\alpha$ ) in the culture supernatants was measured by enzyme-linked immunosorbent assay (ELISA). (D) THP-1 cells were treated at the indicated concentration for $4 \mathrm{~h}$. (E) THP-1 cells were pretreated with MSF at the indicated concentration. After $18 \mathrm{~h}$, the cells were treated with $500 \mathrm{ng} / \mathrm{mL}$ LPS for $4 \mathrm{~h}$. Cell viability was measured using a trypan blue assay. Statistical analysis was conducted with one-way ANOVA followed by Tukey's HSD post hoc test. ${ }^{* *} p<0.001$. 


\subsection{Combination Treatment of LPS and MSF Did Not Inhibit IL-1 $\beta$ Production}

Similarly, LPS increased IL-1 $\beta$ production in THP-1 cells in a dose-dependent manner (Figure 2A). MSF-mediated IL-1 $\beta$ production was more inducible than LPS (Figure 2B). At a concentration of $200 \mu \mathrm{g} / \mathrm{mL}$, MSF induced an approximately 3.5-fold higher level of IL-1 $\beta$ compared to LPS. Unlike TNF- $\alpha$ inhibition, the combination treatment did not inhibit IL-1 $\beta$ production (Figure $2 C$ ). Although a low dose of MSF inhibited LPS-induced IL-1 $\beta$ production, a higher dose of MSF (e.g., $100 \mu \mathrm{g} / \mathrm{mL}$ and $200 \mu \mathrm{g} / \mathrm{mL}$ ) did not. These results suggest that production of TNF- $\alpha$ and IL- $1 \beta$ is regulated by different signaling pathways.

A

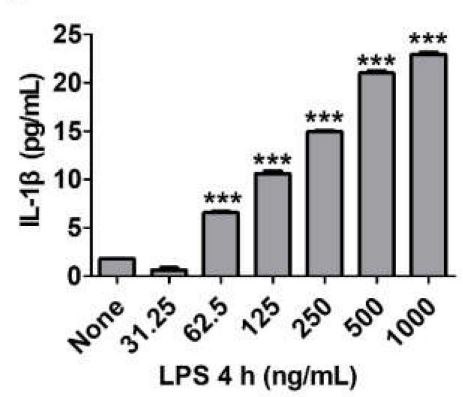

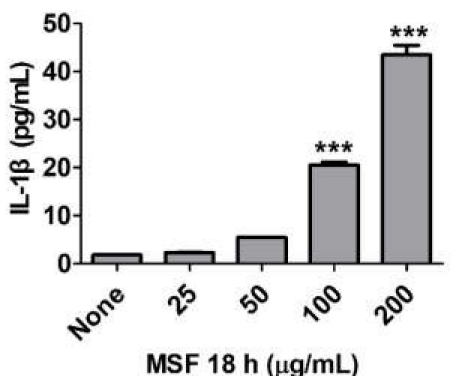

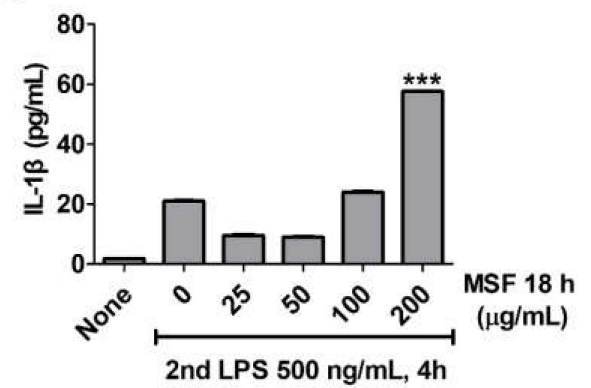

Figure 2. IL-1 $\beta$ expression in THP-1 cells by MSF and LPS treatment. (A) THP-1 cells were treated with LPS at the indicated concentration for $4 \mathrm{~h}$. (B) THP-1 cells were treated with MSF at the indicated concentration for $18 \mathrm{~h}$. (C) THP-1 cells were pretreated with MSF at the indicated concentration for $18 \mathrm{~h}$ and then were retreated with $500 \mathrm{ng} / \mathrm{mL}$ LPS for $4 \mathrm{~h}$. The level of interleukin (IL)-1 $\beta$ in the culture supernatants was measured by ELISA. Statistical analysis was conducted with a one-way ANOVA followed by Tukey's HSD post hoc test. ${ }^{* * *} p<0.001$.

\subsection{TNF- $\alpha$ Tolerance Was More Inducible by MSF Than by K8 Lysates in LPS-Treated THP-1 Cells}

To compare the anti-inflammatory effects of MSF and L. plantarum K8 lysates (K8 lysates), THP-1 cells were treated with each lysate at the indicated concentrations and stimulated with LPS. At a concentration of $200 \mu \mathrm{g} / \mathrm{mL}$, the inhibition of TNF- $\alpha$ expression was $60 \%$ higher with MSF than with K8 lysates (Figure 3A). In addition, the synergistic effect of IL-1 $\beta$ expression was 10\% lower with MSF than with K8 lysates (Figure 3B). These results show that MSF has high anti-inflammatory efficacy, specifically for TNF- $\alpha$.

A

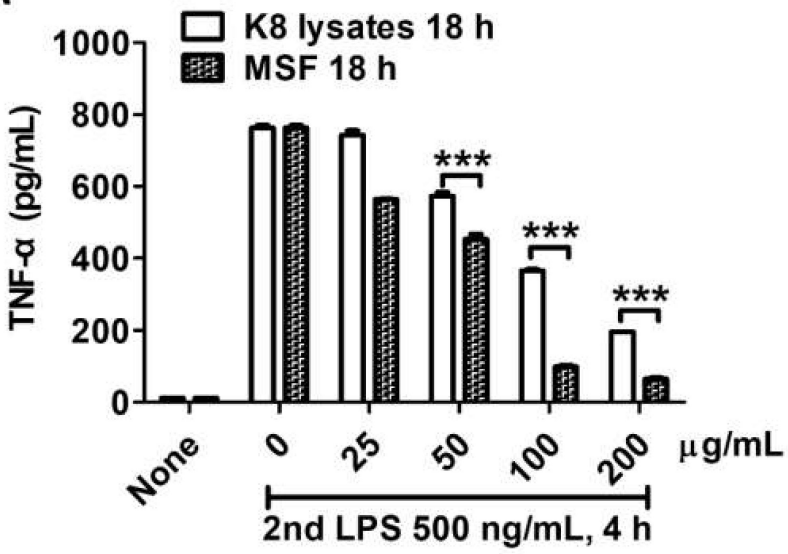

B

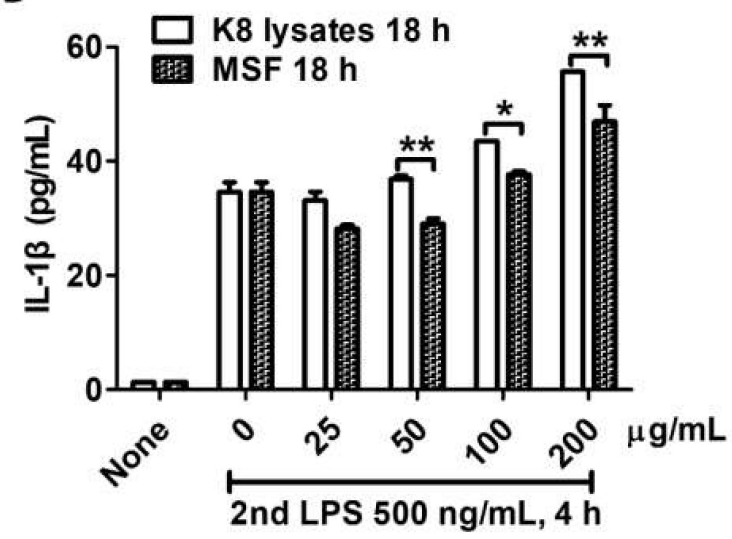

Figure 3. Comparison of anti-inflammatory responses induced by MSF or L. plantarum K8 lysates. (A,B) THP-1 cells were treated with MSF and L. plantarum K8 lysates, respectively, at the indicated concentration for $18 \mathrm{~h}$, and cells were retreated with $500 \mathrm{ng} / \mathrm{mL}$ LPS for $4 \mathrm{~h}$. The levels of cytokines in the culture supernatants were measured by ELISA. Statistical analysis was conducted with two-way ANOVA (G). ${ }^{*} p<0.05 ;{ }^{* *} p<0.01 ;{ }^{* * *} p<0.001$. 


\subsection{Mitogen-Activated Protein Kinase (MAPK) Pathways Were Involved in MSF-Mediated TNF- $\alpha$ Tolerance}

The phosphorylation of MAP kinases (e.g., p38, ERK, and JNK and NF-kB p65 subunits) by LPS and/or MSF was examined by western blot. The phosphorylation of p38, JNK, and p65 was increased by LPS treatment. Among these, p38 and JNK were deactivated by the combined treatment of LPS and MSF. On the other hand, phosphorylation of p65 was stronger when using the combined treatment (Figure 4A). When cells were treated with the indicated inhibitors, TNF- $\alpha$ production was inhibited by p38 and JNK inhibitors, suggesting that both signaling pathways were involved in LPS-mediated TNF- $\alpha$ production (Figure 4B). Taken together, these findings indicate that MSF induces TNF- $\alpha$ tolerance in LPS-treated THP-1 cells by down-regulation of the p38 and JNK pathways. On the other hand, IL-1 $\beta$ production was inhibited by PI3K, NF-kB, and JNK inhibitors (Figure 4C). Considering these data together with Figure 3A, the NF-kB pathway might be involved in IL-1 $\beta$ production in THP-1 cells treated with MSF followed by LPS.

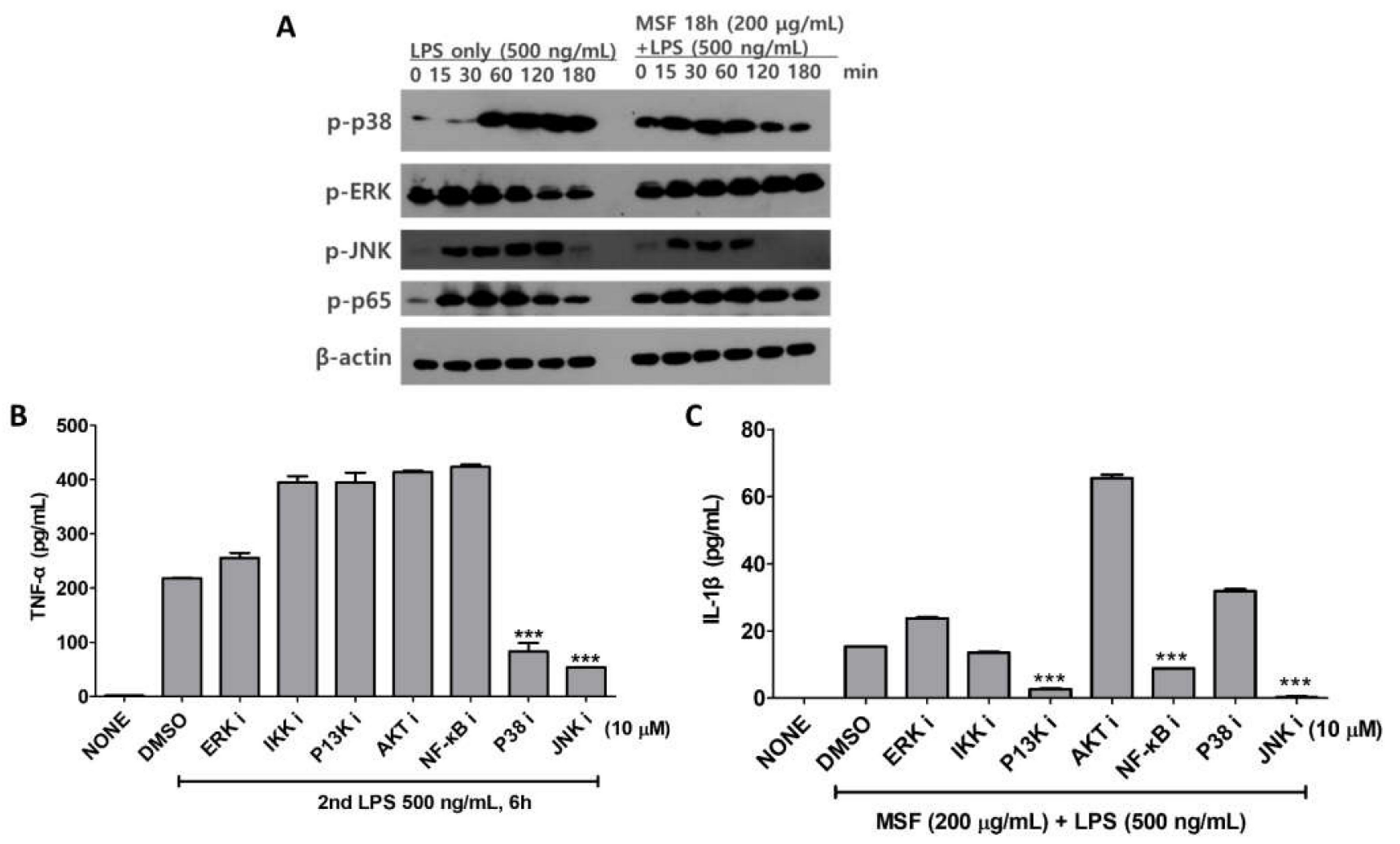

Figure 4. Signaling variation by MSF pretreatment. (A) THP-1 cells were pretreated with $200 \mu \mathrm{g} / \mathrm{mL}$ MSF for $18 \mathrm{~h}$ and then re-stimulated with $500 \mathrm{ng} / \mathrm{mL}$ LPS for the indicated time. The levels of p-p38, p-ERK, p-JNK, p-p65, and $\beta$-actin were then quantified by western blot. (B) THP-1 cells were pretreated with dimethyl sulfoxide (DMSO) as a control and $10 \mu \mathrm{M}$ of inhibitors for $30 \mathrm{~min}$ and re-stimulated with $500 \mathrm{ng} / \mathrm{mL}$ LPS for $4 \mathrm{~h}$. (C) THP-1 cells were pretreated with $200 \mu \mathrm{g} / \mathrm{mL}$ MSF for $18 \mathrm{~h}$ and either DMSO or $10 \mu \mathrm{M}$ of inhibitors for $30 \mathrm{~min}$. The cells were then stimulated with $500 \mathrm{ng} / \mathrm{mL}$ LPS for $4 \mathrm{~h}$. The levels of cytokines in the culture supernatants were measured by ELISA. Statistical analysis was conducted with one-way ANOVA followed by Tukey's HSD post hoc test. ${ }^{* * *} p<0.001$.

\subsection{A20 Was Involved in MSF-Mediated TNF- $\alpha$ Tolerance}

The mRNA levels of negative regulators such as SOCS- 1 and A20 were examined. The SOCS-1 mRNA level increased 4.8-fold, and the A20 mRNA level increased 35-fold in LPS-treated cells compared with untreated controls (Figure 5A,B). In cells treated with only MSF, the SOCS-1 mRNA level did not increase, but the A20 mRNA level increased approximately 20 -fold. A20 mRNA showed the greatest increase (of 60-fold) when THP-1 
cells were co-treated with LPS and MSF (Figure 5B). We further examined the protein levels of the negative regulators by western blot. Similar to mRNA expression, SOCS-1 and A20 proteins were most induced in THP- 1 cells treated with a combination of MSF and LPS (Figure 5C). THP-1 cells were transiently transfected with siRNAs to confirm whether MSF increases the expression of SOCS-1 and A20, which would result in LPSinduced TNF- $\alpha$ tolerance. When cells were transfected with siA20 RNA, MSF-mediated TNF- $\alpha$ inhibition significantly recovered, unlike in siSOCS-1-transfected cells (Figure 5D), suggesting that MSF increased mRNA and protein levels of A20 to inhibit LPS-induced TNF- $\alpha$ production. At a concentration of $200 \mu \mathrm{g} / \mathrm{mL}$, MSF induced $80 \%$ greater A20 protein expression compared to K8 lysates when treated with LPS (Figure 5E), suggesting that the increased TNF- $\alpha$ inhibition by MSF was due to A20 expression.

A

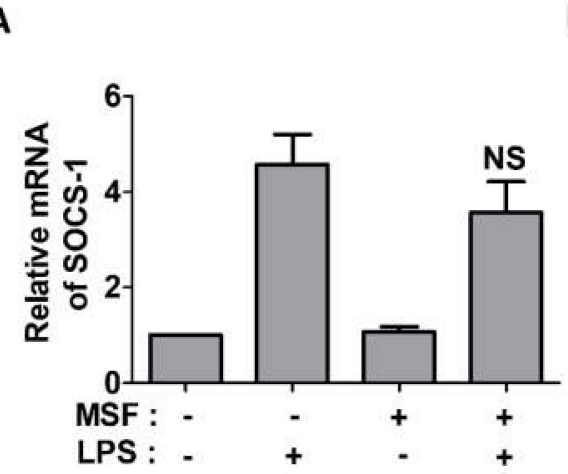

D

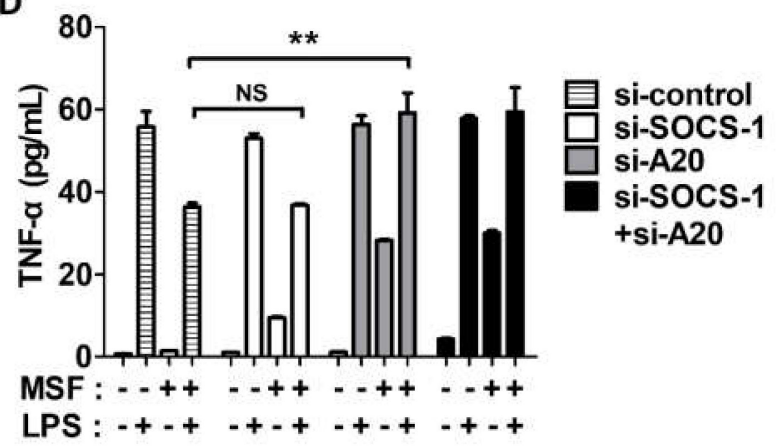

C

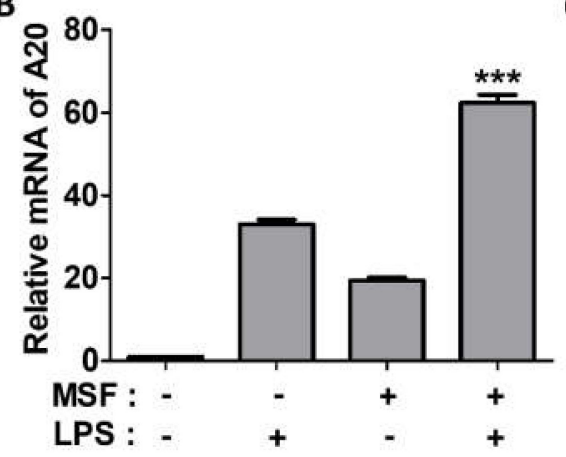

E

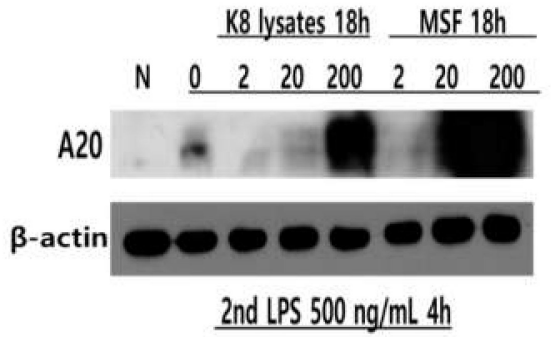

Figure 5. MSF-mediated TNF- $\alpha$ inhibition was associated with negative regulators in the LPS-TLR4 pathway. THP- 1 cells were pretreated with MSF at a concentration of $200 \mu \mathrm{g} / \mathrm{mL}$ for $18 \mathrm{~h}$ and/or stimulated by $500 \mathrm{ng} / \mathrm{mL}$ LPS for $4 \mathrm{~h}$. mRNA levels of suppressor of cytokine signaling 1 (SOCS-1) (A) and tumor necrosis factor $\alpha$-induced protein 3 (TNFAIP3/A20) (B) in total proteins of the cells were then measured by real-time PCR. (C) The levels of SOCS-1 and A20 were quantified by western blot. (D) THP-1 cells were pretreated with $25 \mathrm{nM}$ of siRNA of the control, SOCS-1 and/or A20, respectively, for $36 \mathrm{~h}$. The cells were then treated with $200 \mu \mathrm{g} / \mathrm{mL}$ MSF for $18 \mathrm{~h}$ and/or stimulated by $500 \mathrm{ng} / \mathrm{mL}$ LPS for $4 \mathrm{~h}$. The level of TNF- $\alpha$ in the culture supernatants was measured by ELISA. (E) THP-1 cells were pretreated with $200 \mathrm{MSF} \mu \mathrm{g} / \mathrm{mL}$ or K8 lysates for $18 \mathrm{~h}$ and then re-stimulated with $500 \mathrm{ng} / \mathrm{mL}$ LPS for $4 \mathrm{~h}$. The protein level of A20 was examined by western blot. Statistical analyses were conducted with an unpaired two-tailed $t$-test. NS, not significant; ${ }^{* *} p<0.01 ; * * * p<0.001$.

\subsection{MSF Suppressed LPS-Induced Septic Shock in Mice}

The anti-inflammatory effects of MSF were examined using endotoxin shock induced in mice by LPS. All mice intraperitoneally (i.p.) injected with $10-40 \mathrm{mg} / \mathrm{kg}$ LPS died within $48 \mathrm{~h}$, but $25 \%$ of the mice survived after $10 \mathrm{mg} / \mathrm{kg}$ LPS injection (Figure $6 \mathrm{~A}$ ). No mortality was observed for mice injected with various concentrations of MSF (Figure 6B). Interestingly, pre-injection of MSF ( $400 \mu \mathrm{g} /$ mouse or $4 \mathrm{mg} /$ mouse) in mice $24 \mathrm{~h}$ before injection of $20 \mathrm{mg} / \mathrm{kg}$ LPS improved the survival rate compared with that of mice that only 
received an LPS injection (Figure 6C). All mice pre-injected with K8 lysates died 3 days after LPS injection, while about $38 \%$ of MSF-pre-injected mice survived after LPS injection until the end of the experiment (Figure 6D), suggesting that the MSF-mediated survival rate is superior to that of $\mathrm{K} 8$ lysates.

A
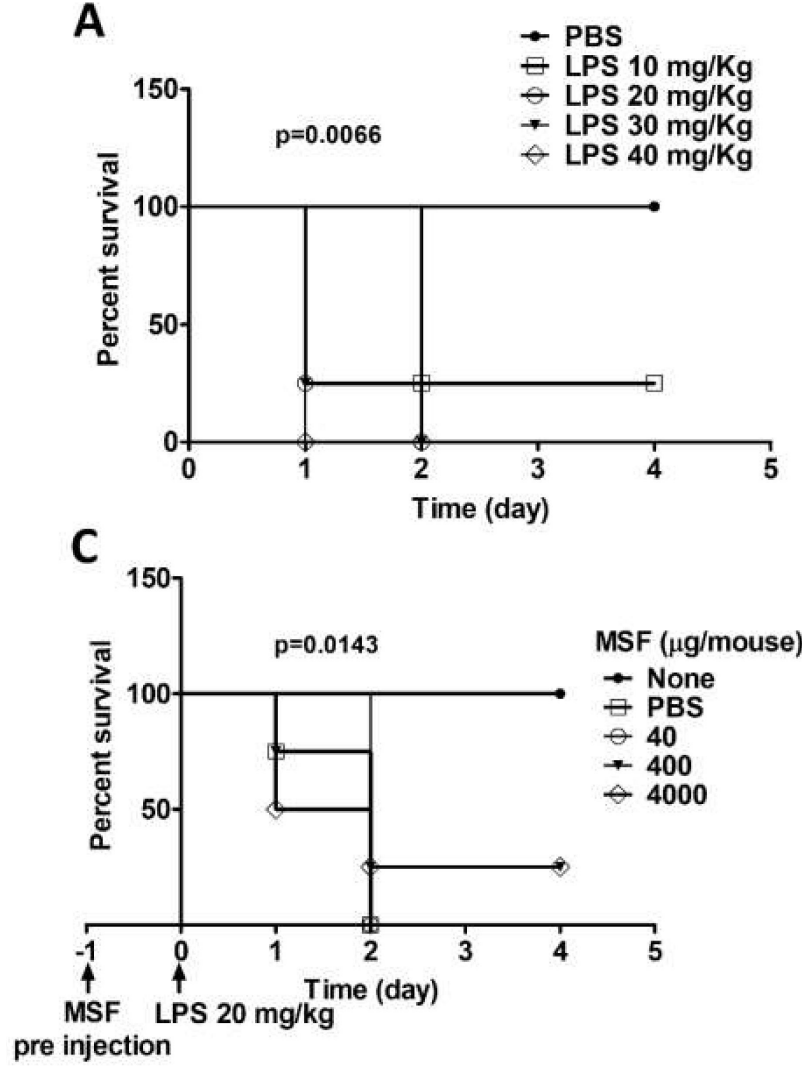

B
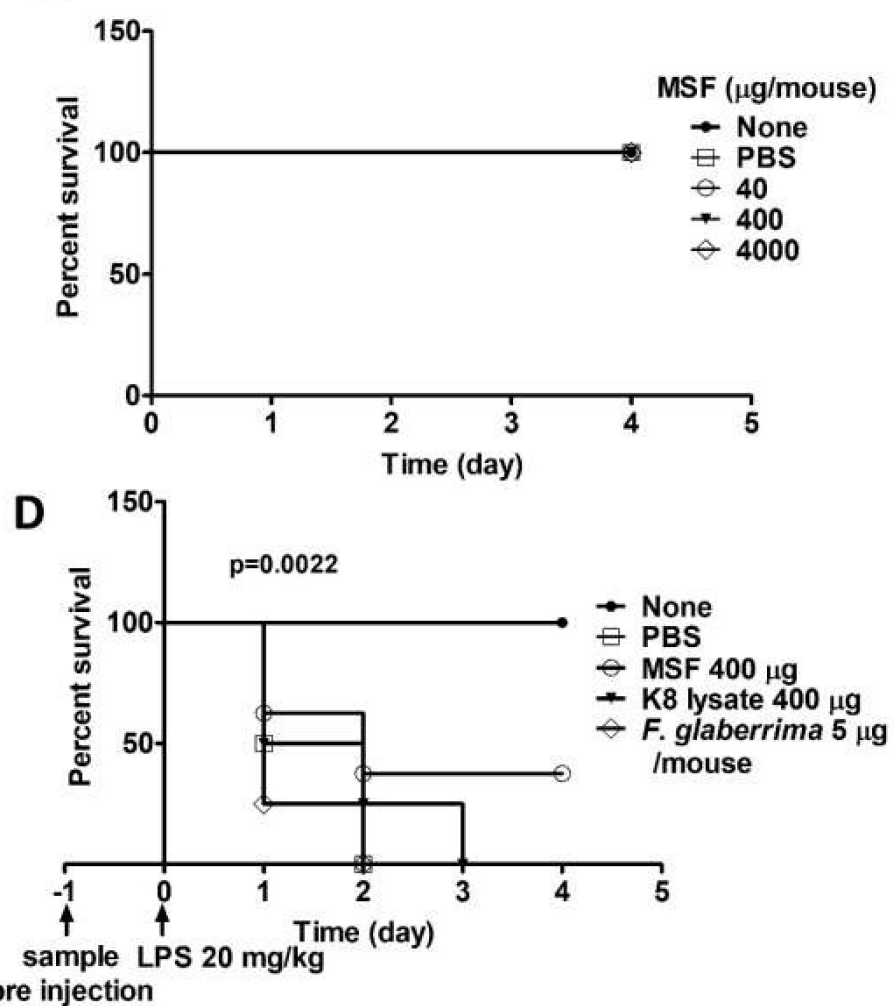

Figure 6. MSF decreased LPS-induced mouse mortality. (A) BALB/c mice (7 weeks old, 8 mice/group) were intraperitoneally (i.p.) injected with LPS at the indicated concentration. $(\mathbf{B})$ Mice $(n=8)$ were i.p. injected with MSF at the indicated concentration. $(\mathbf{C})$ Mice $(n=8)$ were i.p. pre-injected with MSF at the indicated concentration for $24 \mathrm{~h}$ and then re-injected with $20 \mathrm{mg} / \mathrm{kg}$ LPS. (D) Mice $(\mathrm{n}=8)$ were i.p. pre-injected with PBS, $400 \mu \mathrm{g} /$ mouse MSF, $400 \mu \mathrm{g} /$ mouse K8 lysates, or $5 \mu \mathrm{g} / \mathrm{mouse}$ F. glaberrima extracts for $24 \mathrm{~h}$ and then re-injected with $20 \mathrm{mg} / \mathrm{kg}$ LPS. Mouse mortality was observed for 5 days. $p$ values were derived by the log-rank (Mantel-Cox) test using GraphPad Prism 5 software.

In addition, the group subjected to pre-injection with MSF showed decreased serum TNF- $\alpha$ by $25 \%$ and IL- $1 \beta$ by $30 \%$ compared with the mice only injected with LPS. The group subjected to pre-injection with MSF showed decreased serum TNF- $\alpha$ by $15 \%$ and IL-1 $\beta$ by $6 \%$ compared with mice injected with K8 lysates. The group subjected to i.p. pre-injection with F. glaberrima showed similar responses to mice only injected with LPS (Figure 7A,B). The LPS group had higher serum AST and ALT levels than the group without LPS. However, pre-injection with MSF reduced AST by $38 \%$ and ALT by $60 \%$. In addition, the MSF group had lower serum AST and ALT levels than the K8 lysates group, by $14 \%$ and $22 \%$, respectively. The $F$. glaberrima group showed similar responses to mice only injected with LPS (Figure 7C,D). Mice injected with only MSF showed no significant changes in cytokine, AST, and ALT levels compared to those with no MSF. 
A

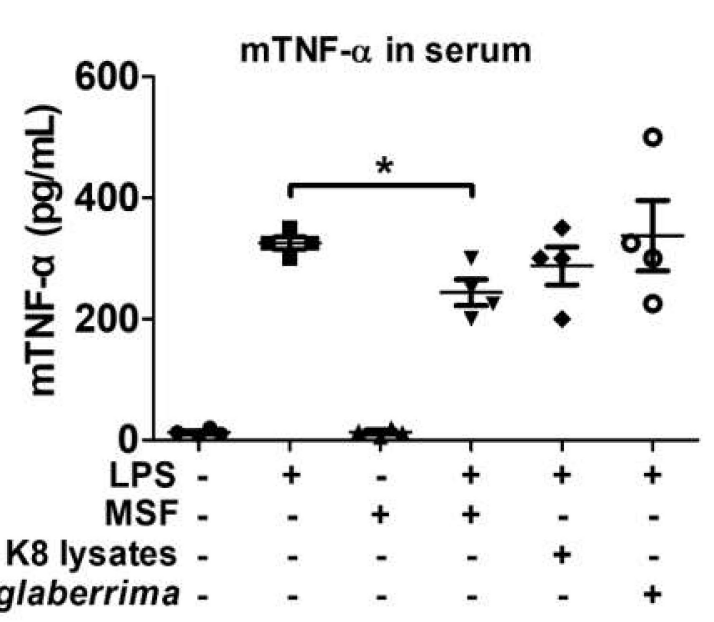

B

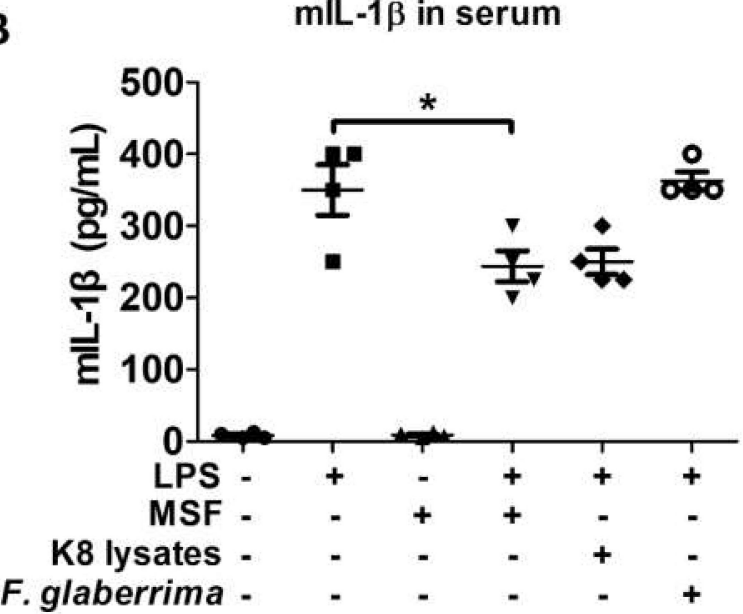

C

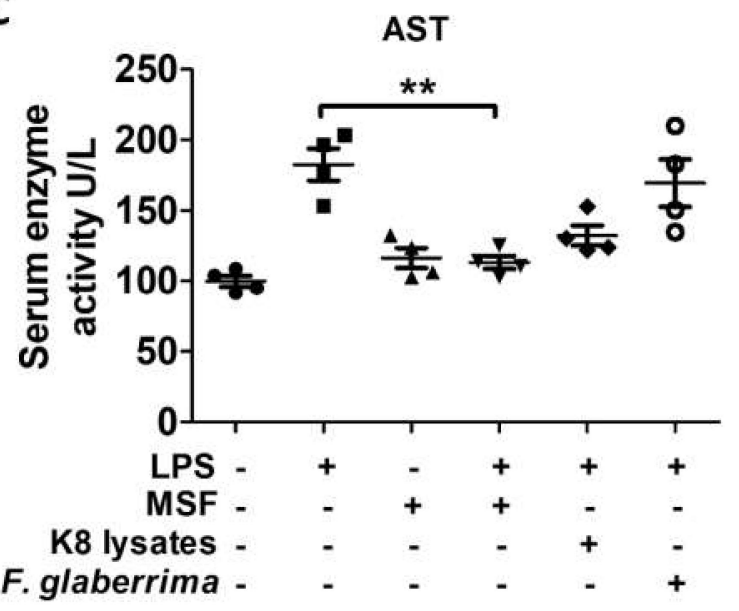

D

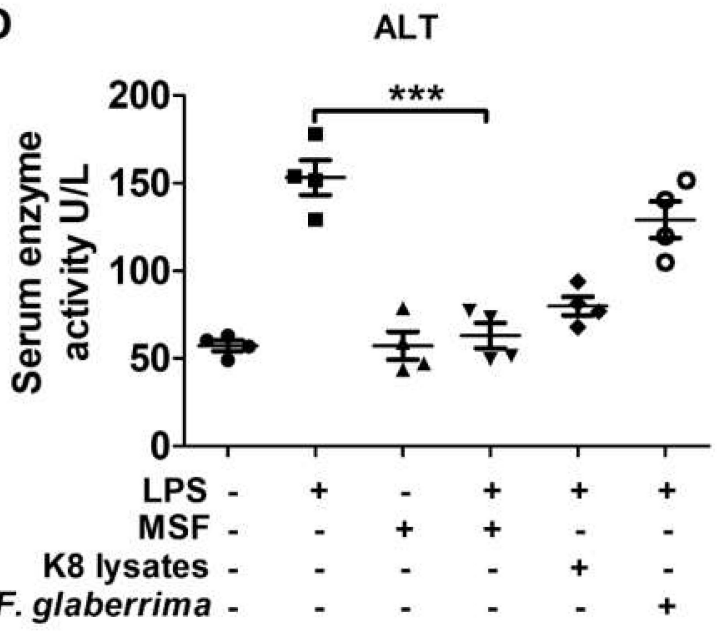

Figure 7. MSF reduced LPS-induced systemic inflammation. BALB/c mice (7 weeks old, 4 mice/group) serum was collected $8 \mathrm{~h}$ after i.p. injection of $20 \mathrm{mg} / \mathrm{kg}$ LPS following pre-injection of PBS, $400 \mu \mathrm{g} / \mathrm{mouse}$ MSF, $400 \mu \mathrm{g} /$ mouse K8 lysates, or $5 \mu \mathrm{g} /$ mouse of F. glaberrima for $24 \mathrm{~h}$. TNF- $\alpha$ (A) and IL-1 $\beta$ (B) levels in the serum were measured by ELISA. Serum AST (C) and ALT (D) levels were observed. Statistical analyses were conducted with an unpaired two-tailed $t$-test. ${ }^{*} p<0.05$; $* * p<0.01 ; * * * 00.001$.

\subsection{MSF Suppressed LPS-Induced Liver Damage}

Next, we examined whether MSF inhibited LPS-induced liver damage in mice. LPS injection triggered an increase in TNF- $\alpha$ and IL-1 $\beta$ in the liver; however, pre-injection with MSF lowered the expression of these cytokines. The levels of TNF- $\alpha$ and IL- $1 \beta$ were lower in the MSF group than in the K8 lysates group. The levels of TNF- $\alpha$ and IL- $1 \beta$ in the F. glaberrima group were similar to those in the LPS group (Figure 8A,B). Similar to the results of in vitro experiments, pre-injection with MSF and re-injection with LPS increased protein expression of the negative regulator A20 (Figure 8C). Immunohistochemistry (IHC) with an antibody for the mouse macrophage receptor F4/80 was performed to evaluate macrophage infiltration. The black part in Figure $8 \mathrm{D}$ represents F4/80, and Figure $7 \mathrm{E}$ represents the relative intensity of the F4/80 area in Figure 8E. An 80\% reduction in macrophage infiltration was observed in mice pre-injected with MSF compared with mice that only received LPS injection. Likewise, macrophage infiltration in the MSF group was lower than that in the K8 lysate group. In an additional study, hepatocyte swelling was observed after LPS injection. However, in mice with MSF pre-injection, the cells were less swollen compared with those in the LPS and K8 lysates groups (Figure 8F). These 
results suggest that MSF reduced the lethality of endotoxin shock in mice by inhibiting inflammatory responses, exhibiting a better preventive effect than K8 lysates.
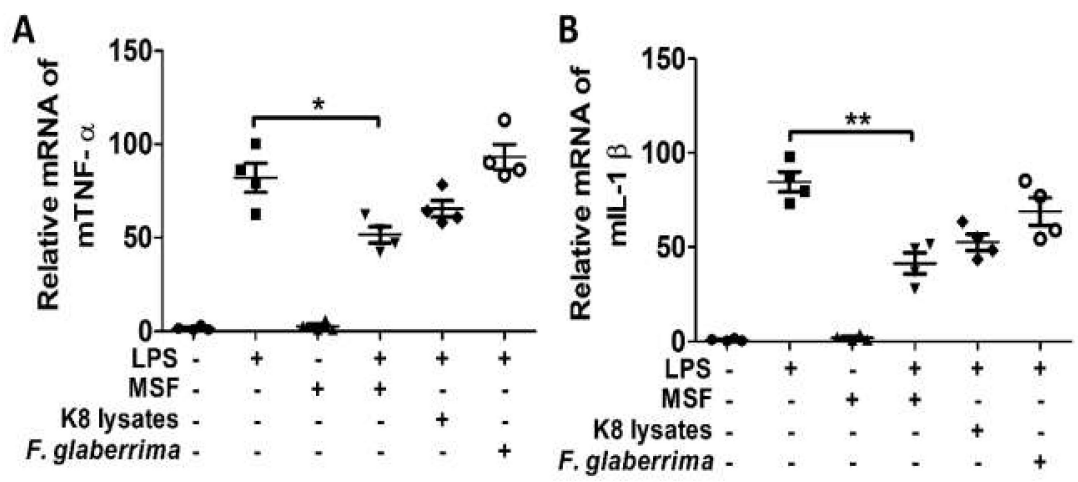

C


Figure 8. MSF reduced LPS-induced liver damage in mice. Liver homogenates of BALB/c mice (7 weeks old, 8 mice/group) were collected $8 \mathrm{~h}$ after i.p. injection of $20 \mathrm{mg} / \mathrm{kg}$ LPS following preinjection of PBS, $400 \mu \mathrm{g} /$ mouse MSF, $400 \mu \mathrm{g} /$ mouse K8 lysates, or $5 \mu \mathrm{g} /$ mouse of F. glaberrima for $24 \mathrm{~h}$. The mRNA levels of TNF- $\alpha$ (A) and IL-1 $\beta$ (B) were measured by real-time PCR. (C) The protein level of A20 was quantified by western blot. (D) Liver immunohistochemistry of F4/80 and (E) relative intensity of F4/80. (F) Liver hematoxylin and eosin staining. Statistical analyses were conducted with an unpaired two-tailed $t$-test. ${ }^{*} p<0.05 ;{ }^{* *} p<0.01$.

\section{Discussion}

The inflammatory response is a biological protective response to external stimuli and is related to immune cells, blood vessels, and inflammatory mediators. The inflammatory response is a double-edged sword, as it serves to block invasion from the outside but can also cause inflammatory diseases. Acute inflammation generally plays a healing role in response to tissue injury, inhibiting cell damage and removing damaged tissue and necrotic cells from a wound [19]. Chronic inflammation can cause various diseases such as allergies, cancer, and arthritis and, in severe cases, can lead to sepsis [20]. It is known that inflammation plays a critical role in the pathogenesis of metabolic syndrome, which increases the risk of heart disease, stroke and type 2 diabetes, atherosclerosis, non-alcoholic fatty liver disease (NAFLD), and obesity [21-23]. Various anti-inflammatory drugs such as nonsteroidal anti-inflammatory drugs (NSAIDs) are used for treatment of inflammatory diseases but are associated with infections and various side effects including gastrointestinal and cardiovascular abnormalities [24,25].

We previously reported that LTA, a cell wall component of L. plantarum K8, has strong anti-inflammatory effects $[12,26]$. Interestingly, L. plantarum K8 LTA does not induce an inflammatory response by itself. Compared with LPS or LTAs isolated from various lactobacillus strains, the anti-inflammatory effect of L. plantarum K8 LTA was superior [12]. L. plantarum K8 LTA was particularly effective in suppressing the excessive expression of TNF- $\alpha$ and IL- $1 \beta$ induced by LPS. Although TNF- $\alpha$ plays an important role in host defense 
against pathogen invasion, dysregulation of TNF- $\alpha$ production has been implicated in a variety of diseases including Alzheimer's disease, cancer, inflammatory bowel disease (IBD), and major depression [27-30]. IL-1 $\beta$ is produced as a proprotein by activated macrophages and is proteolytically processed by caspase- 1 into its active form [31]. IL-1 $\beta$ is involved in a variety of cellular activities, including cell proliferation, differentiation, and apoptosis, but excessive production of IL-1 $\beta$ leads to a variety of auto-inflammatory syndromes [32]. Antiinflammatory effects induced by LTA and lysates have shown differences in the regulation of inflammatory cytokine expression in vitro, while LTA inhibited both TNF- $\alpha$ and IL-1 $\beta$ induced by LPS, lysates inhibited TNF- $\alpha$ while showing a synergistic effect on IL- $1 \beta$. In terms of treatment concentration and efficacy, the anti-inflammatory efficacy of lysates did not attain the level of LTA. Lysates have advantages over LTA in other respects. Specifically, lysates are easy to manufacture and have high safety in storage and use. On the other hand, LTA requires high cost and time to separate and has poor safety, requiring care during storage and use. For these reasons, we attempted to prepare probiotic lysates with superior anti-inflammatory efficacy. Although research using F. glaberrima has not been actively conducted, it has the effect of increasing specific efficacy through fusion with probiotics. MSF prepared through fermentation using F. glaberrima extract showed superior anti-inflammatory efficacy compared to K8 lysates.

Analysis of the flower extract of Filipendula revealed the presence of several polyphenolic constituents including salicylates (e.g., salicylic acid, methylsalicylate, and spiraein), flavonols (e.g., hyperoside, rutin, spiraeoside, and kaempferol 4'-O-glucoside), and ellagitannins (tellimagrandins I and II and rugosin D) [33-35]. In addition, monotropitin, $(+)$-catechin, and $\beta$-sitosterol 3-O- $\beta$ D-glucoside have been isolated from F. glaberrima, and a novel flavonoid glycoside ulmarioside have been isolated from $F$. ulmaria $[17,36]$. Lee et al., have demonstrated that the (+)-catechin content of F. glaberrima was influenced by the flowering stage and geographical location. Samples collected at their early-flowering stage contained higher $(+)$-catechin content than samples collected at their full-flowering stage [37]. The (+)-catechin is the main ingredient found in green tea, and it is a wellknown flavonoid that has many beneficial effects such as antioxidative stress, anti-obesitic, anti-arteriosclerotic, anti-proliferative, and anti-inflammatory activities [38-42]. We hypothesized that the active components of $F$. glaberrima extract were responsible for the increased anti-inflammatory efficacy of MSF. Therefore, we are continuing our research to isolate the active substances from MSF extracts.

Compared with the previously reported anti-inflammatory effects of K8 lysates [11], there are several differences in the anti-inflammatory effects induced by MSF. Whereas K8 lysates induced suppression of TNF- $\alpha$ expression through SOCS-1 and A20, MSF acted only through A20. A20, which regulates the NF-kB signaling pathway, is associated with human diseases such as systemic lupus erythematosus (SLE), rheumatoid arthritis (RA), and Crohn's disease (CD) [43]. In addition, K8 lysates synergistically induced IL-1 $\beta$ expression in combination with LPS, but the MSF and LPS combination did not show this same synergistic effect on IL- $1 \beta$ expression. K8 lysates activated the inflammasome pathway involved in IL-1 $\beta$ secretion upon combination with LPS, whereas this pathway was not activated with the combination of MSF and LPS (data not shown). Although details of this process are unknown, it seems that there are subtle physiological differences between K8 lysates and MSF prepared with F. glaberrima extract. Unlike in vitro experiments, MSF suppressed the expression of IL- $1 \beta$ as well as TNF- $\alpha$ in mouse experiments. Inhibition of systemic inflammation reduced liver damage and mouse mortality induced by LPS.

In conclusion, in the previous study, we have shown that L. plantarum K8 lysates can be used as an anti-inflammatory agent replacement for LTA. Lysates are easier to prepare and less expensive than LTA although a larger amount must be used to achieve the same efficacy. Therefore, in this study, we investigated a method to increase the antiinflammatory efficacy of lysates. We found that this problem could be solved by preparing lysates of probiotics fermented with F. glaberrima extract. MSF is a kind of parabiotics that help maintain immune homeostasis by suppressing excessive inflammatory response. 
Author Contributions: H.K. conceived of and planned the experiments; K.-H.C. and H.K. wrote the manuscript; K.-H.C. and J.H. carried out the experiments; K.-Y.K., S.L. and Y.L. provided raw materials; H.K. and D.-K.C. interpreted the results; D.-K.C. supervised the project. All authors have read and agreed to the published version of the manuscript.

Funding: This study was supported by a grant of the Korea Health Technology R\&D Project, through the Korea Health Industry Development Institute (KHIDI) funded by the Ministry of Health and Welfare (HP20C0226), Korea.

Institutional Review Board Statement: Approval for the mouse experiments was obtained from the Department of Laboratory Animals Institutional Animal Care and Use Committee at the global campus of Kyung Hee University (KHUASP (GC)-18-033, 2018).

Informed Consent Statement: Not applicable.

Data Availability Statement: The data presented in this study are available on request from the corresponding authors.

Conflicts of Interest: The authors declare no conflict of interest.

\section{References}

1. Thakur, K.; Tomar, S.K.; De, S. Lactic acid bacteria as a cell factory for riboflavin production. Microb. Biotechnol. 2016, 9, 441-451. [CrossRef]

2. Wang, Y.; Wu, J.; Lv, M.; Shao, Z.; Hungwe, M.; Wang, J.; Bai, X.; Xie, J.; Wang, Y.; Geng, W.; et al. Metabolism Characteristics of Lactic Acid Bacteria and the Expanding Applications in Food Industry. Front Bioeng. Biotechnol. 2021, 9, 612285. [CrossRef] [PubMed]

3. Jeong, J.H.; Lee, C.Y.; Chung, D.K. Probiotic Lactic Acid Bacteria and Skin Health. Crit. Rev. Food Sci. Nutr. 2016, 56, 2331-2337. [CrossRef]

4. Tang, C.; Kong, L.; Shan, M.; Lu, Z.; Lu, Y. Protective and ameliorating effects of probiotics against diet-induced obesity: A review. Food Res. Int. 2021, 147, 110490. [CrossRef] [PubMed]

5. Tenorio-Jiménez, C.; Martínez-Ramírez, M.J.; Gil, Á.; Gómez-Llorente, C. Effects of Probiotics on Metabolic Syndrome: A Systematic Review of Randomized Clinical Trials. Nutrients 2020, 12, 124. [CrossRef] [PubMed]

6. Mallappa, R.H.; Rokana, N.; Duary, R.K.; Panwar, H.; Batish, V.K.; Grover, S. Management of metabolic syndrome through probiotic and prebiotic interventions. Indian J. Endocrinol. Metab. 2012, 16, 20-27.

7. Behera, S.S.; Ray, R.C.; Zdolec, N. Lactobacillus plantarum with Functional Properties: An Approach to Increase Safety and Shelf-Life of Fermented Foods. Biomed. Res. Int. 2018, 2018, 9361614. [CrossRef]

8. Morshedi, M.; Hashemi, R.; Moazzen, S.; Sahebkar, A.; Hosseinifard, E.S. Immunomodulatory and anti-inflammatory effects of probiotics in multiple sclerosis: A systematic review. J. Neuroinflamm. 2019, 16, 231. [CrossRef]

9. Choi, S.H.; Lee, S.H.; Kim, M.G.; Lee, H.J.; Kim, G.B. Lactobacillus plantarum CAU1055 ameliorates inflammation in lipopolysaccharide-induced RAW264.7 cells and a dextran sulfate sodium-induced colitis animal model. J. Dairy Sci. 2019, 102, 6718-6725. [CrossRef]

10. Han, K.J.; Lee, J.-E.; Lee, N.-K.; Paik, H.-D. Antioxidant and Anti-Inflammatory Effect of Probiotic Lactobacillus plantarum KU15149 Derived from Korean Homemade Diced-Radish Kimchi. J. Microbiol. Biotechnol. 2020, 30, 591-598. [CrossRef]

11. Kim, G.; Choi, K.H.; Kim, H.; Chung, D.K. Alleviation of LPS-Induced Inflammation and Septic Shock by Lactiplantibacillus plantarum K8 Lysates. Int. J. Mol. Sci. 2021, 22, 5921. [CrossRef]

12. Kim, H.G.; Kim, N.R.; Gim, M.G.; Lee, J.M.; Lee, S.Y.; Ko, M.Y.; Kim, J.Y.; Han, S.H.; Chung, D.K. Lipoteichoic acid isolated from Lactobacillus plantarum inhibits lipopolysaccharide-induced TNF-alpha production in THP-1 cells and endotoxin shock in mice. $J$. Immunol. 2008, 180, 2553-2561. [CrossRef] [PubMed]

13. Barros, L.; Cabrita, L.; Boas, M.V.; Carvalho, A.M.; Ferreira, I.C.F.R. Chemical, biochemical and electrochemical assays to evaluate phytochemicals and antioxidant activity of wild plants. Food Chem. 2011, 127, 1600-1608. [CrossRef]

14. Shilova, I.V.; Semenov, A.A.; Suslov, N.I.; Korotkova, E.I.; Vtorushina, A.N.; Belyakova, V.V. Chemical composition and biological activity of a fraction of meadowsweet extract. Pharm. Chem. J. 2009, 43, 185-190. [CrossRef]

15. Harbourne, N.; Marete, E.; Jacquier, J.C.; Riordan, D.O. Stability of phytochemicals as sources of anti-inflammatory nutraceuticals in beverages-A review. Food Res. Int. 2013, 50, 480-486. [CrossRef]

16. Katanić, J.; Tatjana, B.; Nevena, S.; Vladimir, M.; Milan, M.; Samo, K.; Miroslav, M.V. Bioactivity, stability and phenolic characterization of Filipendula ulmaria (L.) Maxim. Food Funct. 2015, 6, 1164-1175. [CrossRef]

17. Yeo, H.; Kim, J.; Chung, B.S. Phytochemical studies on the constituents of Filipendula glaberrima. Kor. J. Pharmacogn. 1992, 23, 121-125.

18. Popa, C.; Netea, M.G.; van Riel, P.L.; van der Meer, J.W.; Stalenhoef, A.F. The role of TNF-alpha in chronic inflammatory conditions, intermediary metabolism, and cardiovascular risk. J. Lipid Res. 2007, 48, 751-762. [CrossRef] 
19. Chen, L.; Deng, H.; Cui, H.; Fang, J.; Zuo, Z.; Deng, J.; Li, Y.; Wang, X.; Zhao, L. Inflammatory responses and inflammationassociated diseases in organs. Oncotarget 2017, 9, 7204-7218. [CrossRef]

20. Weiss, U. Inflammation. Nature 2008, 454, 427. [CrossRef]

21. Sutherland, J.P.; McKinley, B.; Eckel, R.H. The metabolic syndrome and inflammation. Metab. Syndr. Relat Disord. 2004, 2, 82-104. [CrossRef]

22. Hu, R.; Xie, Y.; Lu, B.; Li, Q.; Chen, F.; Li, L.; Hu, J.; Huang, Y.; Li, Q.; Ye, W.; et al. Metabolic inflammatory syndrome: A novel concept of holistic integrative medicine for management of metabolic diseases. AME Med. J. 2018, 3, 4. [CrossRef]

23. Grundy, S.M. Inflammation, Metabolic Syndrome, and Diet Responsiveness. Circulation 2003, 108, 126-128. [CrossRef] [PubMed]

24. Patil, K.R.; Mahajan, U.B.; Unger, B.S.; Goyal, S.N.; Belemkar, S.; Surana, S.J.; Ojha, S.; Patil, C.R. Animal Models of Inflammation for Screening of Anti-inflammatory Drugs: Implications for the Discovery and Development of Phytopharmaceuticals. Int. J. Mol. Sci. 2019, 20, 4367. [CrossRef] [PubMed]

25. Toussi, S.S.; Pan, N.; Walters, H.M.; Walsh, T.J. Infections in children and adolescents with juvenile idiopathic arthritis and inflammatory bowel disease treated with tumor necrosis factor- $\alpha$ inhibitors: Systematic review of the literature. Clin. Infect. Dis. 2013, 57, 1318-1330. [CrossRef] [PubMed]

26. Kim, H.G.; Lee, S.Y.; Kim, N.R.; Ko, M.Y.; Lee, J.M.; Yi, T.H.; Chung, S.K.; Chung, D.K. Inhibitory effects of Lactobacillus plantarum lipoteichoic acid (LTA) on Staphylococcus aureus LTA-induced tumor necrosis factor-alpha production. J. Microbiol Biotechnol. 2008, 18, 1191-1196.

27. Swardfager, W.; Lanctôt, K.; Rothenburg, L.; Wong, A.; Cappell, J.; Herrmann, N. A meta-analysis of cytokines in Alzheimer's disease. Biol. Psychiatry 2010, 68, 930-941. [CrossRef] [PubMed]

28. Locksley, R.M.; Killeen, N.; Lenardo, M.J. The TNF and TNF receptor superfamilies: Integrating mammalian biology. Cell 2001, 104, 487-501. [CrossRef]

29. Dowlati, Y.; Herrmann, N.; Swardfager, W.; Liu, H.; Sham, L.; Reim, E.K.; Lanctôt, K.L. A meta-analysis of cytokines in major depression. Biol. Psychiatry 2010, 67, 446-457. [CrossRef]

30. Brynskov, J.; Foegh, P.; Pedersen, G.; Ellervik, C.; Kirkegaard, T.; Bingham, A.; Saermark, T. Tumour necrosis factor alpha converting enzyme (TACE) activity in the colonic mucosa of patients with inflammatory bowel disease. Gut 2002, 51, 37-43 [CrossRef]

31. Latz, E.; Xiao, T.S.; Stutz, A. Activation and regulation of the inflammasomes. Nat. Rev. Immunol. 2013, 13, 397-411. [CrossRef] [PubMed]

32. Mantovani, A.; Dinarello, C.A.; Molgora, M.; Garlanda, C. Interleukin-1 and Related Cytokines in the Regulation of Inflammation and Immunity. Immunity 2019, 50, 778-795. [CrossRef] [PubMed]

33. Gupta, R.K.; Al-Shafi, S.M.K.; Layden, K.; Haslam, E. The metabolism of gallic acid and hexahydroxydiphenic acid in plants. Part 2. Esters of (S)-hexahydroxydiphenic acid with D-glucopyranose (4C1). J. Chem. Soc. Perkin Trans. 1982, 1, 2525-2534. [CrossRef]

34. Okuda, T.; Yoshida, T.; Hatano, T.; Iwasaki, M.; Kubo, M.; Orime, T.; Yoshizaki, M.; Naruhashi, N. Hydrolyzable tannins as chemotaxonomic markers in the Rosaceae. Phytochemistry 1992, 31, 3091-3096. [CrossRef]

35. Pemp, E.; Reznicek, G.; Krenn, L. Fast quantification of flavonoids in Filipendulae ulmariae flos by HPLC/ESI-MS using a nonporous stationary phase. J. Anal. Chem. 2007, 62, 669-673. [CrossRef]

36. Olennikov, D.N.; Kruglova, M.Y. A new quercetin glycoside and other phenolic compounds from the genus Filipendula. Chem. Nat. Compd. 2013, 49, 610-616. [CrossRef]

37. Lee, H.D.; Lee, Y.; Kim, H.; Kim, H.; Park, C.-G.; Lee, S. HPLC/UV Quantification of (+)-Catechin in Filipendula glaberrima from Different Regions and Flowering Stages. Kor. J. Pharmacogn. 2020, 51, 291-296.

38. Dong, P.; Pan, L.; Zhang, X. Hawthorn (Crataegus pinnatifda Bunge) leave flavonoids attenuate atherosclerosis development in apoE knock-out mice. J. Ethnopharmacol. 2017, 19, 479-488. [CrossRef]

39. George, S.; Ajikumaran Nair, S.; Johnson, A.J.; Venkataraman, R.; Baby, S. O-prenylated flavonoid, an antidiabetes constituent in Melicope lunu-ankenda. J. Ethnopharmacol. 2015, 168, 158-163. [CrossRef]

40. Kassim, M.; Achoui, M.; Mustafa, M.R.; Mohd, M.A.; Yusoff, K.M. Ellagic acid, phenolic acids, and flavonoids in Malaysian honey extracts demonstrate in vitro anti-inflammatory activity. Nutr. Res. 2010, 30, 650-659. [CrossRef]

41. Moghaddam, G.; Ebrahimi, S.A.; Rahbar-Roshandel, N.; Foroumadi, A. Antiproliferative activity of flavonoids: Influence of the sequential methoxylation state of the flavonoid structure. Phytother. Res. 2012, 26, 1023-1028. [CrossRef] [PubMed]

42. Zeng, Q.; Zhang, X.; Xu, X. Antioxidant and anticomplement functions of flavonoids extracted from Penthorum chinense Pursh. Food Funct. 2013, 4, 1811-1818. [CrossRef] [PubMed]

43. Das, T.; Chen, Z.; Hendriks, R.W.; Kool, M. A20/Tumor Necrosis Factor $\alpha$-Induced Protein 3 in Immune Cells Controls Development of Autoinflammation and Autoimmunity: Lessons from Mouse Models. Front. Immunol. 2018, 9, 104. [CrossRef] [PubMed] 